\title{
Laurent Cognet
}

\author{
A new imaging approach forged by deep friendships, joining two fields and two selves.
}

\section{II} have a double life in science," says physicist Laurent Cognet. His double lives-one devoted to studying the physics of carbon nanotubes and the other focused on bioimaging-began after he had completed his $\mathrm{PhD}$ degree in cold atom physics at Paris Sud University. He's now a research director with the French national science agency CNRS, through which he is a scientist at the University of Bordeaux's optics institute.

A physicist by heart, conviction and training, but curious about biology, Cognet sought to look at biological questions through the eyes of a physicist. As a postdoctoral fellow he worked on singlemolecule microscopy techniques with Thomas Schmidt at Leiden University studying the movement of molecules in membranes.

After that, he landed a position in Bordeaux to work with Brahim Lounis and also Michel Orrit, who pioneered single-molecule detection in fluorescence microscopy. There, in collaboration with others, Cognet first detected single molecules in a neuronal membrane with a microscope he had custom-built. He remembers exclaiming “They move!" when he saw the movement of neurotransmitter receptors in a synaptic membrane.

\section{Science is a meeting between people.}

He spent a CNRS- and Fulbrightfinanced sabbatical at Rice University-his wife and three children came along-and he explored the many open questions about the physics of carbon nanotubes. "And, at the same time," he says, "I always had that in mind: what can I do with those in biology?"

In recent years, Cognet has been merging his two lives. Part of that merging is the development of SELFI, a method that enhances the possibilities of 3D superresolution imaging in tissues ${ }^{1}$. Typically, aberration muddies the view when researchers try to image tissue regions deeper than the top layer of cells. SELFI

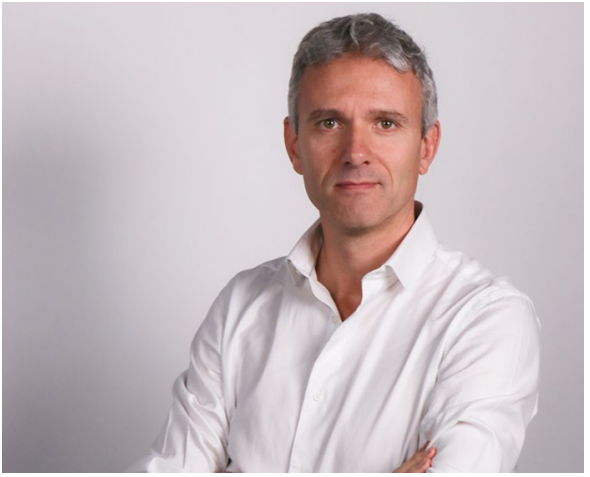

Laurent Cognet (Image: P. Bon)

harnesses the principles of self-interference such that single molecules can be localized as deep as $50 \mu \mathrm{m}$ in tissue.

The method addresses axial blur in ways other methods such as astigmatic microscopy cannot. Those approaches essentially encode a position of a molecule based on aberration, says Cognet. When additional aberration comes into play as a result of sample-related issues, "nothing works," he says. It becomes impossible to measure a molecule's position accurately. With SELFI, "the beam is self-referenced by itself," he says. The team figured out how to generate interferences that cancel out aberrations along the path of light. To do so, they designed a diffraction grating and developed software to interpret the interferogram.

With SELFI, Cognet and his lab encode the axial position based on phase imaging, which leverages a light trait that is less sensitive to aberration. Bringing together phase imaging and fluorescence microscopy is a way to "use another property of the light people didn't use before for that," says Cognet. "Instead of looking at intensity you look at the phase of the light."

The method can be combined with different super-resolution microscopy techniques. The team did so with SELFISTORM, and it could work with SELFIPALM or SELFI-PAINT, he says. "Next steps will be: go into infrared, mix it with my favorite nanotubes," he says about his future SELFI projects.

The SELFI concept grew out of discussions in the lab, mainly between Cognet and Pierre Bon, a phase imaging microscopist and the paper's first author. "Science is a meeting between people," says Cognet. To him, human interactions are a key factor when doing science.

Scientific friendships are important to Cognet and he cultivates them with coauthors and collaborators in the lab, next door and halfway across the world. Friendships in science take trust, he says. Stealing ideas from others might lead to a paper, he says, but "then you lose a friend." Discussing science with friends makes him happy. "That is why I am doing this job," he says.

When Cognet is not in the lab or cultivating science friendships, he spends time with family and friends. "I like visual things; I guess that's what put me in optics," he says. He enjoys art, photography and using all senses. "I'm a French guy, I like food, I love wine and coffee," he says, adding that this might be typical for someone who lives in Bordeaux. He is serious about wine and oenology. Wine appeals to the senses and pairs well with friendships, he says. Both take patience and are shaped by time.

Cognet feels inspired by Orrit, whom he counts as a friend. Cognet's culture ranges from nanometers to millimeters, from cold atoms to brain physiology, says Orrit. His "flair for selecting questions and methods matches his care in collecting fine Bordeaux wines," he says. "Laurent's sunny character makes science relaxed as well as enthralling, both for his group and his colleagues."

\section{Vivien Marx}

Published online: 31 May 2018

https://doi.org/10.1038/s41592-018-0013-3

References

1. Bon, P. et al. Self-interference 3D super-resolution microscopy for deep tissue investigations. Nat. Methods https://doi.org/10.1038/ s41592-018-0005-3 (2018). 